\title{
Use of a side-cutting aspiration device for resection of tumors during endoscopic endonasal approaches
}

\author{
Victor Garcia-Navarro, M.D., ${ }^{1}$ Guido Lancman, B.A., ${ }^{1}$ \\ Amancio Guerrero-Maldonado, M.D., ${ }^{1}$ ViJay K. Anand, M.D., ${ }^{2}$ \\ AND ThEOdORE H. SChWARTZ, M.D. ${ }^{1-3}$ \\ Departments of ${ }^{1}$ Neurosurgery, ${ }^{2}$ Otolaryngology, and ${ }^{3}$ Neurology and Neuroscience, Weill Cornell Medical \\ College, New York Presbyterian Hospital, New York, New York
}

\begin{abstract}
Object. Accessing intra- and extradural tumors via an endonasal approach requires working safely in a relatively narrow area with unobstructed visibility. The authors describe their experience to highlight the utility of a side-cutting aspiration device for endoscopic endonasal resection of skull base tumors.

Methods. The authors used this device in 13 nonconsecutive endoscopic endonasal procedures for different skull base tumors ( 8 pituitary macroadenomas, 2 craniopharyngiomas, 1 chordoma, 1 recurrent ependymoma, and 1 lymphoma). Illustrative cases and video are presented to demonstrate its use.

Results. The instrument was easy to use and effective in the removal of the lesions presented in this series. In 10 patients (77\%), gross-total resection was possible; in the other 3 patients $(23 \%)$, more than $80 \%$ of the tumor was resected. No collateral tissue damage or any other complication resulted from device-related debulking or aspiration.

Conclusions. The side-cutting tissue resector is a safe, easy to use, and effective tool for internal debulking and extracapsular dissection of nonvascularized tumors that are too firm for bimanual suction or blunt ring curette dissection. It is particularly useful when working through a deep and narrow corridor such as is encountered in endoscopic endonasal skull base surgery. (DOI: 10.3171/2011.1.FOCUS10302)
\end{abstract}

KEY WoRDS $\bullet$ skull base $\bullet$ endoscopy $\bullet$ minimally invasive procedure $\bullet$
craniopharyngioma $\bullet$ chordoma $\bullet$ transsphenoidal surgery

$\mathrm{T}$ HE introduction of novel surgical approaches has always required the design and development of specific instruments based on the particular needs of the approach. The endonasal corridor is a long, narrow channel and the limited maneuverability requires the design of specific, dedicated instruments. ${ }^{1}$

One of the challenges of the endonasal endoscopic cranial base approach for resecting large, firm tumors has been the lack of adequate instruments to debulk the tumor. Although long narrow ultrasonic aspirators exist, their narrow center tube can clog with particulate material. Likewise, the tip of the instrument, where the aspiration occurs, is not easily visualized with a colinear, parallel endoscope, which provides better visualization for the side of the instrument. ${ }^{4,5}$

Craniopharyngiomas, adenomas, and chordomas have a recurrence rate directly correlated with the percent of resection..$^{11}$ An ideal instrument for achieving this goal using endoscopic visualization would be a long,

narrow side-cutting instrument whose tip and noncutting side could be placed in proximity to critical neurovascular structures for resection of firm tumors in a narrow working space without heating the surrounding tissue.

\section{Methods}

\section{Equipment and Principles}

We used such a side-cutting aspiration system called the NICO Myriad (NICO Myriad System, NICO Corp.). The device is available in 3 lengths $(10,13$, and $25 \mathrm{~cm})$ and 2 cannula diameters ( 1.9 and $2.5 \mathrm{~mm}$ ). The handpiece is shown in Fig. 1. The mechanism at the tip is based on a device that acts as an aspirator, tissue rake, and scissors. It is a disposable, nonheat-generating tissue removal system. It has an outer stationary cannula and a blunt atraumatic tip. An orifice on the side of the outer cannula is located several millimeters from the tip. A bladed inner 
cannula slides up and down within the outer cannula and is connected to a motor-driven handpiece. The functions of the device, suction, and blade action are controlled by a foot pedal, which can be variably depressed to regulate the degree of suction and the rapidity of the reciprocating blade. Tissue drawn into the central core by suction is cut by the reciprocating action of the bladed inner cannula (Fig. 1). ${ }^{7}$ In addition, the tip can be bent up to $30^{\circ}$ with a bending tool provided by the company, and tissue can be collected in a collection vat placed in-line with the suction of the device to collect tissue for pathological examination or a tumor bank.

\section{Patient Population}

We reviewed a prospectively collected database of all endoscopic endonasal surgeries performed at Weill Cornell Medical College, New York Presbyterian Hospital, between October 2009 and October 2010, as a collaboration between the neurosurgery and otolaryngology departments. Of the total 59 patients, 13 patients (22\%) (with only giant pituitary adenomas, ependymomas, craniopharyngiomas, and chordomas) underwent endoscopic endonasal surgery in which the NICO Myriad system was used. The aformentioned tumors are generally firm and not amenable to just the 2-suction technique.

\section{Surgical Technique}

A surgical team that included an otolaryngologist (V.K.A.) and a neurosurgeon (T.H.S.) performed the extended endonasal surgeries at the Institute for Minimally Invasive Skull Base and Pituitary Surgery, Weill Cornell Medical College/New York Presbyterian Hospital. Institutional review board approval was obtained for the study. All procedures were performed using frameless stereotactic image guidance (BrainLab). The surgical technique for the endoscopic endonasal skull base approach has been described. ${ }^{6,8-10}$ Once the approach was completed and the tumor exposed, the NICO Myriad was used to internally decompress the tumor in preparation for sharp extracapsular dissection (Video 1).

VIDEO 1. Use of a side-cutting aspiration device for resection of tumors during endoscopic endonasal approaches. Click here to view with Windows Media Player. Click here to view with Quicktime.

\section{Results}

We used the NICO Myriad in a series of 13 cases. The pathology of the cases is presented in Table 1 . We found the instrument most helpful in the following situations. 1) Giant pituitary macroadenomas-these tumors tend to be very firm and difficult to resect with only ring curettes or straight suction. The NICO Myriad was extremely useful at internal decompression of these tumors so the capsule could be identified for extracapsular dissection (see Case 1). 2) Chordomas-these lesions can be soft and easily resected with suction or extremely firm and fibrous. In the latter case, the NICO Myriad is extremely useful to remove fibrous chordomas. In addition, the blunt tip of the device can be placed against the dura

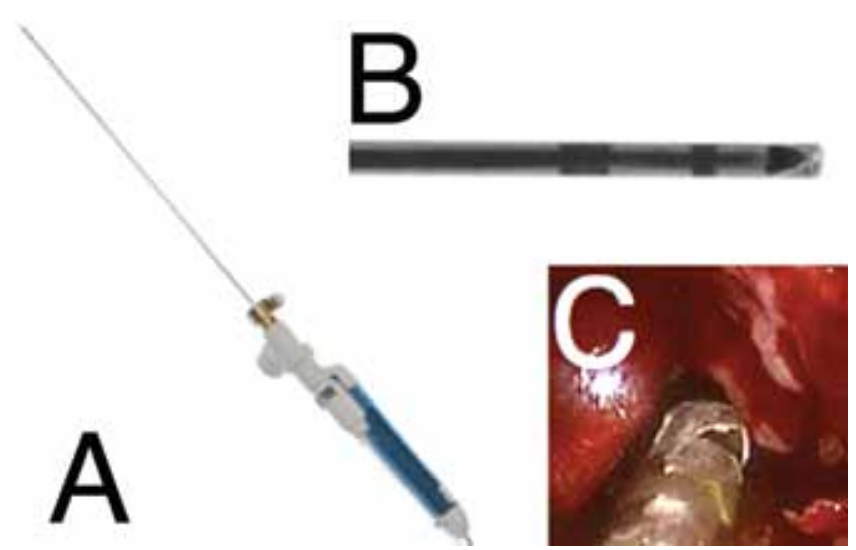

Fig. 1. A: Side-cutting aspiration device (handpiece). B: Close-up view of the nontraumatic blunt tip. C: The side port for aspiration of tissue.

behind the clivus to remove the tumor and ensure that the dura is not opened inadvertently. 3) Craniopharyngiomas - the firm, solid parts of craniopharyngiomas, particularly those that extend into the third ventricle, can be difficult to remove with suction alone. The NICO Myriad can be bent upwards and placed into the third ventricle to remove solid intraventricular craniopharyngiomas via an endonasal approach (see Case 2).

The instrument was easy to use and effective in the removal of the lesions presented in this series, even when the consistency of the lesion was extremely firm and fibrous. In 6 of 8 adenomas, gross-total resection was performed. In both of the other cases the patients had cavernous sinus tumor extension, but more than $80 \%$ of the lesion was resected in each case. The clival chordoma, suprasellar craniopharyngioma, and recurrent ependymoma of the brainstem were totally resected. One patient diagnosed with lymphoma underwent partial resection. No intra- or postoperative complications occurred in this series. Closure was performed using either 1) a fat graft held in place with a Medpore (Porex Corp.) buttress covered with a nasoseptal flap and Duraseal (Confluent Surgical, Inc.) for adenomas with CSF leakage or 2) a gasketseal closure covered with a nasoseptal flap and Duraseal for the craniopharyngioma. There were no postoperative CSF leaks.

\section{Illustrative Cases}

\section{Case 1}

This 78-year-old man presented with progressive gait trouble, urinary incontinence, change in mental status, and bitemporal hemianopsia. A solid enhancing sellar-suprasellar mass and mild hydrocephalus were identified on MR imaging. An extended transsphenoidal approach was used with transtuberculum, transplanum removal. The tumor was first removed from within the sella. The optic chiasm was elevated and the tumor was removed from beneath the optic chiasm and the third ventricle. Internal decompression was performed until the walls of the third ventricle were identified and the tumor was considered to be completely removed. The foramina of Monro and the 


\section{Side-cutting aspiration for endoscopic endonasal resection}

TABLE 1: Summary of tumor diagnosis, tumor extension, and extent of resection in 13 patients*

\begin{tabular}{cllll}
\hline Case No. & \multicolumn{1}{c}{ Diagnosis } & \multicolumn{1}{c}{ Extension† } & \multicolumn{1}{c}{ Consistence } & Extent of Resection \\
\hline 1 & macroadenoma & suprasellar- parasellar & firm & GTR \\
2 & macroadenoma & parasellar (cav sinus) & soft & GTR \\
3 & macroadenoma & parasellar (cav sinus) & extremely firm/fibrous & STR \\
4 & macroadenoma & suprasellar & extremely firm/fibrous & GTR \\
5 & macroadenoma & suprasellar & firm & GTR \\
6 & macroadenoma & parasellar (cav sinus) & firm & STR \\
7 & macroadenoma & suprasellar & soft & GTR \\
8 & recurrent macroadenoma & suprasellar & extremely firm/fibrous & GTR \\
9 & craniopharyngioma & suprasellar & extremely firm/fibrous & GTR \\
10 & craniopharyngioma & suprasellar & extremely firm/fibrous & GTR \\
11 & chordoma & clival: CVJ & extremely firm/fibrous & GTR \\
12 & recurrent ependymoma & clival: brainstem & extremely firm/fibrous & GTR \\
13 & lymphoma & suprasellar & firm & STR \\
\hline
\end{tabular}

* cav = cavernous; CVJ = craniovertebral junction; GTR = gross-total resection; STR = subtotal resection.

$\dagger$ Parasellar includes into or beneath cavernous sinus, and anterior, middle, or posterior fossa extension.

choroid plexus were seen, and the skull base was closed (Fig. 2).

\section{Case 2}

This 60-year-old man had a history of craniopharyngioma, which was partially resected by bifrontal craniotomy and treated with CyberKnife 1 year prior to our evaluation. He presented with progressive visual reduction and diabetes insipidus. The patient underwent endoscopic gross-total tumor resection via a transsellar, trans- planum, transtuberculum approach. The tumor was identified above the normal pituitary gland. It was dissected free from the surrounding structures and internally decompressed with the NICO Myriad device. Using a $30^{\circ}$ endoscope, the lesion was dissected free from the optic chiasm and the cyst was removed from the third ventricle. The floor of the hypothalamus was free of tumor. The third ventricle was visualized superiorly. There was no evidence of residual tumor. The diagnosis was adamantinomatous craniopharyngioma (Fig. 3).

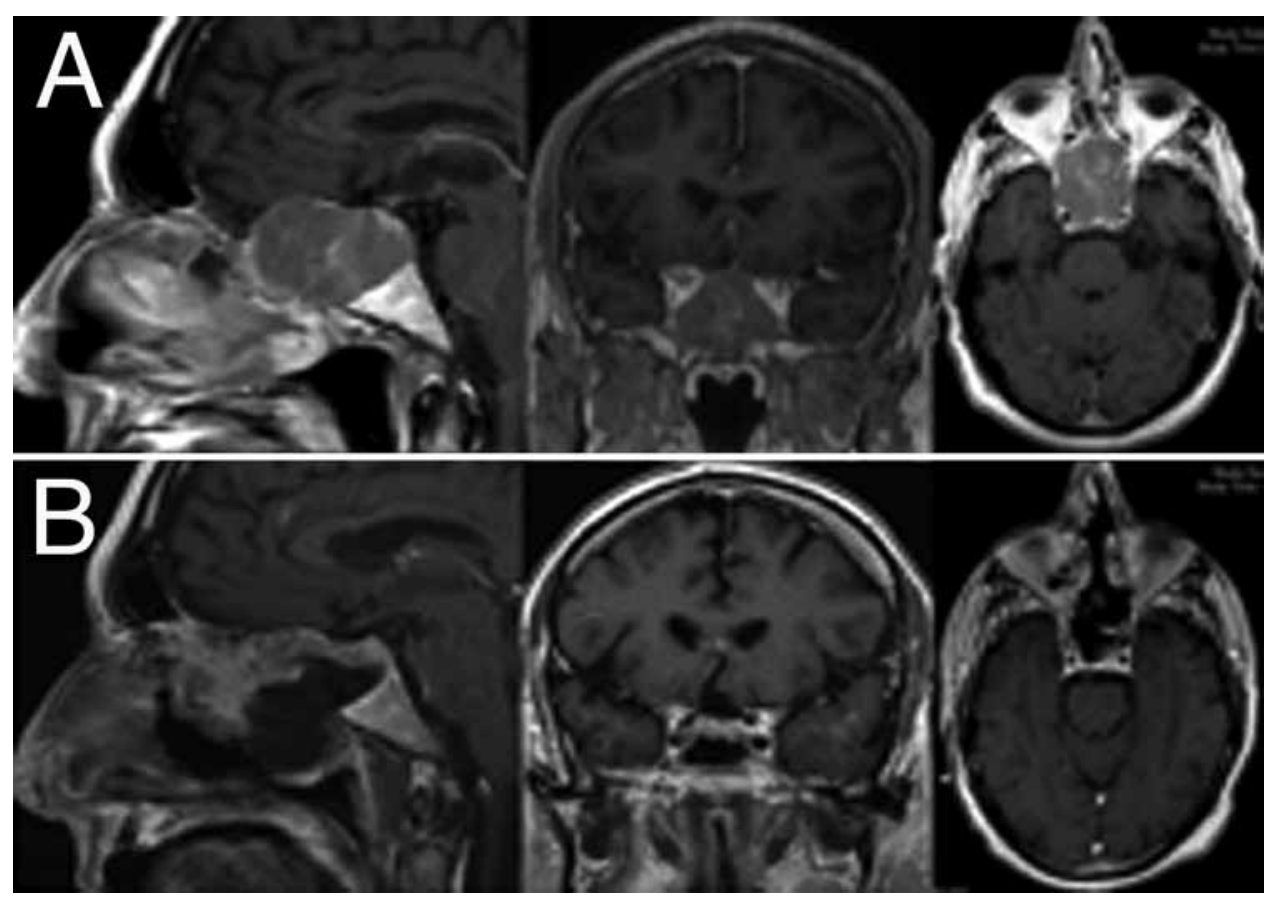

Fig. 2. Case 1. A: Preoperative sagittal, coronal, and axial T1-weighted MR images demonstrating a large mass extending into the suprasellar cistern and compressing the optic chiasm. B: Postoperative T1-weighted MR images confirming gross-total resection of the tumor. 

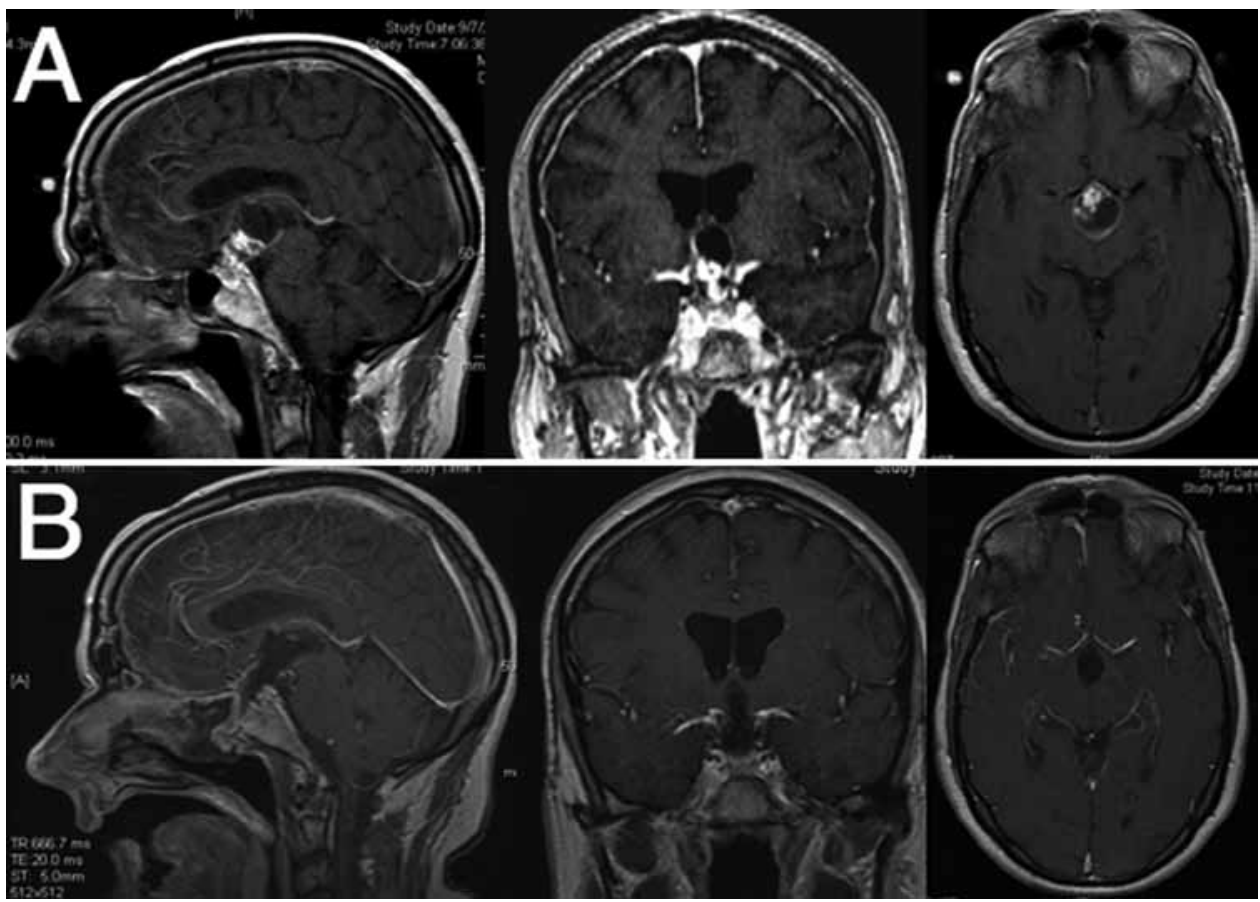

FIG. 3. Case 2. A: Preoperative sagittal, coronal, and axial T1-weighted MR images showing a mixed cystic and solid sellar and suprasellar mass and enhancement of the solid portion and the peripheral rim of the cystic portion. B: Postoperative T1weighted MR images confirming gross-total resection of the tumor.

\section{Case 3}

This 68-year-old man developed diplopia 3 months before evaluation, which lasted 2 weeks and slowly resolved. After that he had pressure behind his right eye related to a headache, which was graded at 7/10. On physical examination he had an early upper temporal quadrantic visual loss. Magnetic resonance imaging revealed a large expansive and destructive mass, arising from an expanded sella and extending into the sphenoid sinus. There was extension into the anterior cranial fossa through a dehiscence of the ethmoid roof and cribriform plate. There was extraconal extension into the orbits.

An endoscopic endonasal approach, with sphenoidectomy and ethmoidectomy, was performed and the tumor was identified. The tumor was internally decompressed using the NICO Myriad. As the tumor was being debulked, the pathology report returned indicating a possible lymphoma and the resection was halted with some residual tumor left in the orbit and ethmoid roof (Fig. 4).

\section{Discussion}

The most important criteria for new instrument design in endoscopic endonasal surgery are that the device: 1) move easily and safely in a limited surgical corridor, 2) be well balanced and ergonomic for safe handling, while avoiding any conflict between the surgeon's hands, the endoscope, and other instruments that may be present in the same nostril, and 3) allow the surgeon to work in every visible zone of the surgical field provided by the endoscope. . $^{2,3}$

The NICO Myriad tissue removal system is highly useful in tumor resection. It is lightweight, requires the use of only 1 hand, and features both tissue cutting and removal without the use of heat or ultrasonic energy, which reduces the chance of collateral damage. Because the end of the device is closed and blunt, there is little danger of injuring vessels or other fragile structures obscured from view by the instrument itself. ${ }^{7}$ However, the surgeon must be aware of the possibility of adjacent tissue being aspirated into the device and causing iatrogenic damage. These complications can be avoided by intracapsular debulking of the tumor followed by extracapsular dissection. The NICO device is useful first to internally decompress firm tumors. We select this tool mainly for giant adenomas, chordomas, and craniopharyngiomas. We have found that these tumors are usually not amenable to resection using merely bimanual suction and blunt ring curette dissection. Once free of critical surrounding neurovascular structures, the NICO Myriad can be placed on the tumor capsule with the cutting side inwards and the noncutting side on the neurovascular structures to safely remove the remainder of the tumor. Alternating between these 2 techniques has been extremely valuable in removing large firm tumors. In addition, the NICO Myriad can be bent and the tip advanced up into the third ventricle. This maneuver is extremely useful for removing tumor fragments in the suprasellar cistern that may be beyond the reach of angled suctions.

Alternatives to the NICO Myriad are the ultrasonic aspirator, the Elliquence, and bimanual suction. In our experience, the transsphenoidal tips to the ultrasonic aspirator often clog with particulate material and their diameter is not as small and low profile as desired. The Elliquence is excellent for meningiomas that are too firm for the NICO Myriad and vascular but is not useful for 


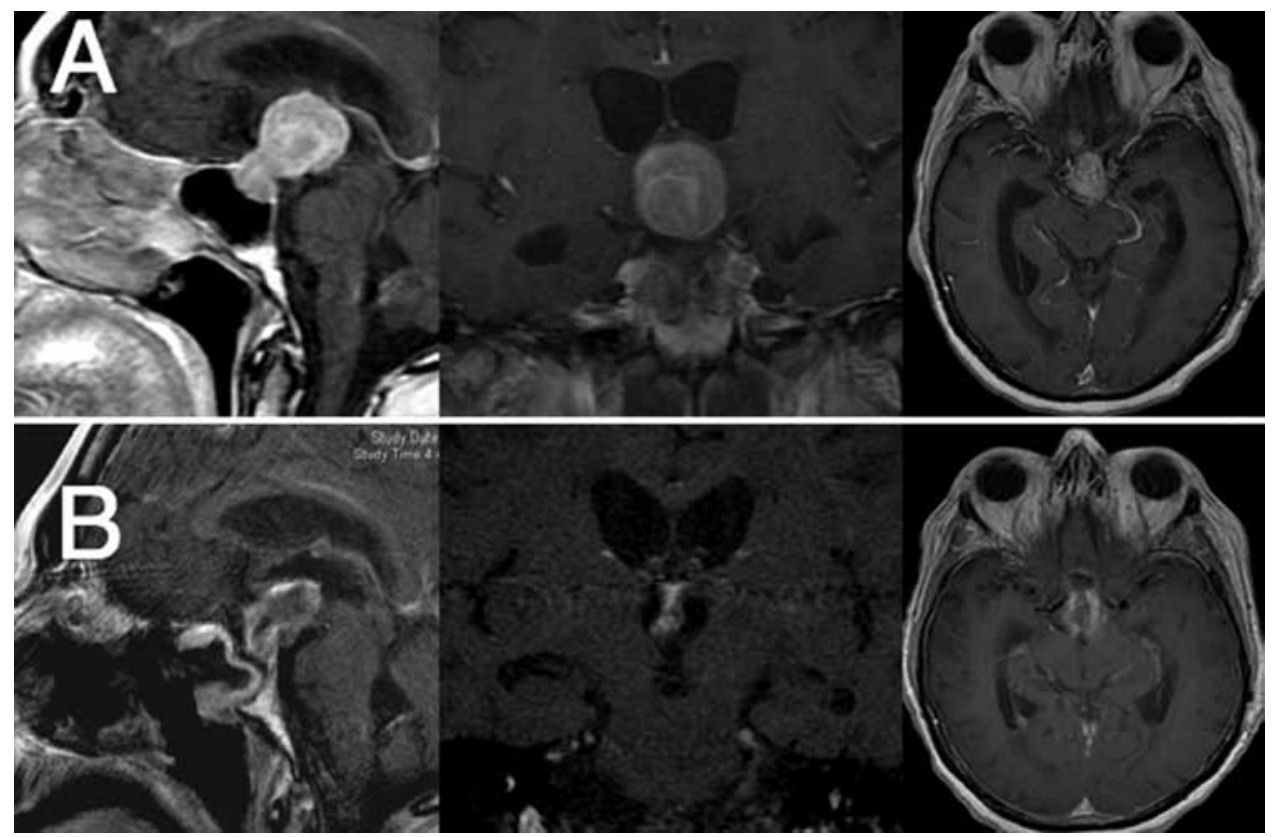

FIG. 4. Case 3. A: Preoperative sagittal, coronal, and axial T1-weighted MR images showing a large expansive and destructive mass extending into the sphenoid sinus, sellar and suprasellar area. B: Postoperative T1-weighted MR images confirming subtotal resection of the lesion.

tumors that are fibrous and avascular such as chordomas and macroadenomas. Bimanual suction is excellent for soft tumors, but once tumors become fibrous, this method often is not adequate. The NICO Myriad fills gaps in existing instrumentation.

The cost of the NICO Myriad is not insubstantial since there is a fixed cost for the main unit and additional costs for each disposable handpiece. We have found the NICO Myriad to be only useful for a small percentage of our cases, roughly $20 \%$. However, for the cases in which the device was used, its use was thought to be almost essential to obtain a complete resection in a reasonable time period. For this reason, we feel that the NICO Myriad is worth the cost, even though it is only used in a subset of our cases. Whether the NICO Myriad leads to significant increases in extent of resection or survival is not known and would require a randomized trial. Such a trial will likely never be done, since it has not even been performed to justify the multimillion dollar acquisition of intraoperative MR imagers.

\section{Conclusions}

The NICO Myriad tissue removal system is a safe, easy to use, and effective tool when used for internal debulking and extracapsular dissection of nonvascularized tumors that are too firm for bimanual suction or blunt ring curette dissection. It is particularly useful when working through a deep and narrow corridor such as is encountered in endoscopic endonasal skull base surgery.

\section{Disclosure}

The authors report no conflict of interest concerning the material or methods used in this study or the findings specified in this paper. None of the authors has any financial interest in any device discussed in this paper.

Author contributions to the study and manuscript preparation include the following. Conception and design: Garcia-Navarro, Guerrero-Maldonado, Schwartz. Acquisition of data: GarciaNavarro, Lancman. Analysis and interpretation of data: GarciaNavarro, Guerrero-Maldonado. Drafting the article: Garcia-Navarro, Lancman. Critically revising the article: Anand, Schwartz. Reviewed final version of the manuscript and approved it for submission: all authors. Administrative/technical/material support: Garcia-Navarro, Lancman. Study supervision: Anand, Schwartz.

\section{References}

1. Cappabianca P, Cavallo LM, Esposito I, Barakat M, Esposito F: Bone removal with a new ultrasonic bone curette during endoscopic endonasal approach to the sellar-suprasellar area: technical note. Neurosurgery 66 (3 Suppl Operative):E118, 2010

2. Cappabianca P, de Divitiis O, Esposito F, Cavallo LM, de Divitiis E: Endoscopic skull base instrumentation, in Anand VK, Schwartz TH (eds): Practical Endoscopic Skull Base Surgery. San Diego: Plural Publishing, 2007, pp 45-56

3. Cappabianca P, Esposito F, Cavallo LM, Corriero OV: Instruments, in Cappabianca P, Califano L, Iaconetta G (eds): Cranial, Craniofacial and Skull Base Surgery. Milan: Springer, 2010, pp 7-15

4. Cavallo LM, Prevedello D, Esposito F, Laws ER Jr, Dusick JR, Messina A, et al: The role of the endoscope in the transsphenoidal management of cystic lesions of the sellar region. Neurosurg Rev 31:55-64, 2008

5. Fraser JF, Nyquist GG, Moore N, Anand VK, Schwartz TH: Endoscopic endonasal transclival resection of chordomas: operative technique, clinical outcome, and review of the literature. Clinical article. J Neurosurg 112:1061-1069, 2010

6. Laufer I, Anand VK, Schwartz TH: Endoscopic, endonasal extended transsphenoidal, transplanum transtuberculum approach for resection of suprasellar lesions. J Neurosurg 106: 400-406, 2007 


\section{Garcia-Navarro et al.}

7. Lekovic GP, Gonzalez LF, Feiz-Erfan I, Rekate HL: Endoscopic resection of hypothalamic hamartoma using a novel variable aspiration tissue resector. Neurosurgery 58 (1 Suppl): ONS166-ONS169, 2006

8. Leng LZ, Brown S, Anand VK, Schwartz TH: "Gasket-seal" watertight closure in minimal-access endoscopic cranial base surgery. Neurosurgery 62 (5 Suppl 2):ONSE342-ONSE343, 2008

9. Placantonakis DG, Tabaee A, Anand VK, Hiltzik D, Schwartz TH: Safety of low-dose intrathecal fluorescein in endoscopic cranial base surgery. Neurosurgery 61 (3 Suppl):161-166, 2007

10. Tabaee A, Anand VK, Brown SM, Lin JW, Schwartz TH: Algorithm for reconstruction after endoscopic pituitary and skull base surgery. Laryngoscope 117:1133-1137, 2007

11. Van Effenterre R, Boch AL: Craniopharyngioma in adults and children: a study of 122 surgical cases. J Neurosurg 97:3-11, 2002

Manuscript submitted December 14, 2010.

Accepted January 17, 2011.

Supplemental online information:

Video: http://mfile.akamai.com/21490/wmv/digitalwbc.download. akamai.com/21492/wm.digitalsource-na-regional/focus10-302.asx (Media Player).

http://mfile.akamai.com/21488/mov/digitalwbc.download.akamai. com/21492/qt.digitalsource-global/focus10-302.mov (Quicktime).

Address correspondence to: Theodore H. Schwartz, M.D., Department of Neurosurgery, Weill Cornell Medical College, 525 East 68th Street, Box \#99, New York, New York 10065. email: schwarh@ med.cornell.edu. 